\title{
EARLY DETECTION OF VESSEL COLLISION SITUATIONS IN A VESSEL TRAFFIC SERVICES AREA
}

\author{
Igor RUDAN ${ }^{*}$, Vlado FRANČIĆ ${ }^{2}$, Marko VALČIĆ ${ }^{3}$, Matthew SUMNER ${ }^{4}$ \\ ${ }^{1,2}$ Faculty of Maritime Studies, University of Rijeka, Rijeka, Croatia \\ ${ }^{3}$ Faculty of Engineering, University of Rijeka, Rijeka, Croatia \\ ${ }^{4}$ Höegh LNG AS, Oslo, Norway
}

Received 6 July 2018; revised 4 January 2019, 18 March 2019; accepted 22 March 2019; first published online 18 November 2019

\begin{abstract}
This study presents enhanced collision detection model in a Vessel Traffic Services (VTS) area. The proposed detection method of collision situations is based on the assumption that VTS station is provided with passage plans of all the vessels in a monitored area. By using an early detection model for prediction of possible collision situations, VTS stations could switch from the area-monitoring concept to the passage-monitoring system. An early detection model of collision risks in a VTS area uses vessels' dynamic characteristics as inputs (vessels' position, course over ground and speed), and delivers prediction of their future positions as output. In order to achieve the desired accuracy, the model takes into the account the intended course alterations and the impending environmental loads. The model is able to provide the outputs as early as the passage plans are submitted to a VTS monitored area. Hence, when discussing model's capability for early detection of collision situations, improved VTS operating standards could be developed in order to achieve safer passages through enhanced collision avoidance strategies. Simulation results clearly show the advantages of the proposed model as a decision support tool for a VTS operator when combining passage plans with the analysis of environmental loads.
\end{abstract}

Keywords: vessel, passage plan, VTS, collision early detection, collision avoidance, position prediction.

\section{Introduction}

The number of merchant fleets is increasing together with the immense traffic flows and highly dense maritime traffic within main ports and corridors. Vessel traffic flow is closely related to navigation safety and efficiency and has received considerable attention in the research field of marine traffic engineering (Liu et al. 2017). In their study on collision avoidance in busy waterways, Mou et al. (2010) stated that without traffic management and services, collision occurrences would climb proportionally with the intensity of traffic. Gran (1999) similarly concluded that the potential for collision is higher in high-density traffic areas when compared with less immense corridors. Many recent case studies demonstrate that dynamic collision avoidance studies will continue to play significant role in shaping traffic management systems.

Global economy growth depends largely on undisrupted traffic of goods. Increased population, diversity of demands, open markets and ease of communication have contributed to the steady development of shipping sector with constant rise in number of available vessels (ISL 2018), as well as to their size and speed. Vessel Traffic Service (VTS) areas measure dense traffic propagations that require more efficient control of maritime traffic, all in order to reduce collision risks (Kop 1990; Tsou 2010a).

Maritime traffic control may be divided into two segments: navigation control performed by masters/officers on board vessels, and vessel traffic control performed by the VTS operators. In order for the VTS to be effective in monitoring traffic situations, it is important that the service has an option of generating, receiving, processing and broadcasting important navigational information. This is achieved by integrating messages containing relevant data from Automatic Radar Plotting Aid (ARPA), Automatic Identification System (AIS), Electronic Chart Display and Information System (ECDIS), Closed-Circuit TeleVision (CCTV), Very High Frequency (VHF), compass and other devices used for safe navigation. Functionality of the VTS system has significantly increased by collecting AIS data,

${ }^{*}$ Corresponding author. E-mail: rudan@pfri.hr 
and therefore, many new possibilities of its development have sprung up (Kao et al. 2007; Ou, Zhu 2008; Tsou 2010a). Improved means for vessel control and communication (Donderi et al. 2004; Ou, Zhu 2008), as well as the option of controlling the entire navigable area from the VTS operations centre, provide the operators with a better overview of maritime traffic than that of the officers and masters on board vessels.

This paper proposes a proactive approach to maritime traffic control based on the passage plans and dynamic data received from vessels before reaching the monitored area. This allows VTS operators to evaluate passage plans and detect close-quarter situations by using proposed early collision situations detection model. However, the proposed model provides a decision support tool for a VTS operator, but it is important to point out that it does not provide a solution with the appropriate actions that should be carried out in a situation when possible collision situations are detected. By its nature, the model is adaptive because voyage-planned vessel speeds are adjusted for the effects of meteorological and oceanological conditions. In other words, any model for estimation of vessel speed under different environmental loads (Kim et al. 2017; Mao et al. 2016; Prpić-Oršić, Faltinsen 2012; Valčić et al. 2011) can be easily integrated within the proposed model. Early detection of collision situations in congested traffic areas based on this approach has the significant potential for the improvement of the navigation safety and preservation of the environment.

\section{Review and fundamentals}

The development of risk models very much depends on the quality of the data inputs that are stochastic by nature. In order to reduce probabilistic uncertainties, this paper introduces an early detection model in the VTS controlled area. Considering that the passage plans would be submitted to VTS control centres in advance, the potential collision situations could be significantly reduced. The prerequisite of this approach is directly related to the development of a common format and architecture for the exchange of route information and voyage plans together with the major manufacturers of navigational equipment (STM 2015). In this context, an appropriate concept of shared real-time voyage plans has been already introduced (STM 2018a; Lind et al. 2018), while the validation of this overall sea traffic management concept is still in the ongoing phase (STM 2018b).

In order to improve maritime safety, the research community is committed to find root causes of collisions. When assessing the consequences, it is important to evaluate the actual circumstances of an event, rather than to base collision risk models solely on historic data. The goal of the risk detection models is to eliminate close encounters by incorporating various inputs, such as weather and sea conditions, collision angle, vessels' speeds, and various ship's dynamics (Goerlandt, Kujala 2011).
There are several approaches that use AIS data for resolving collision risk difficulties. Tsou (2016) adopted ECDIS as an information platform together with the AIS real time data to develop predicted areas of danger. This model incorporated spatial data from Electronic Navigation Charts (ENC) and used Geographic Information System (GIS) data together with collision regulations to develop decision support system able to cope with multiple targets and geographical obstacles when proposing a route to the user. Zhang et al. $(2015,2016)$ developed an approach for detecting potential near misses based on AIS data and also explored the limits of such approach (Last et al. 2015). Sang et al. (2015) considered inland waterway ship trajectories based on the AIS collected data in order to verify manoeuvring characteristics and ship-handling behaviours. Mou et al. (2010) presented linear regression model of collision risks in busy waterways using AIS data in Port of Rotterdam in order to identify the correlation of Closest Point of Approach (CPA) with ship's size, speed and course.

Detecting collision risks by using modern control systems is usually limited due to VTS operators' engagement with monitoring and processing of the data collected from the vessels. Westerlund (2010) research shows that, in cases of high maritime traffic density, manual detection of all unconventional navigation situations in the VTS area is almost impossible. Consequently, many accidents at sea have occurred without the VTS operators noticing them; this may be due to the lack of quality of warning systems (Kao et al. 2007). Research to date shows that there is a need for improvement of maritime traffic control (Westerlund 2010; Bukhari et al. 2013; Filipowicz 2004; Kao et al. 2007; Ou, Zhu 2008; Su et al. 2012; Tsou 2010a).

The appropriate level of accuracy within passage plans would greatly facilitate the early detection of potentially dangerous situations. Current regulations state that ships' passage planning must be prepared from berth to berth, taking into the account numerous parameters (Tsou $2010 \mathrm{~b}$ ). Passage plans of all ships in the monitored area could be sent to the VTS centre via the AIS system (Harati-Mokhtari et al. 2007), whereas the data concerning the intended passage could also be sent as part of the navigation data (Ou, Zhu 2008).

In addition to integrating passage planning into decision support models, one of the primary purposes of navigation control is detecting and dealing with collision situations. Although most collisions can be attributed to human error (Chauvin et al. 2013; Filipowicz 2004; Rudan et al. 2012) increasing traffic density and average vessels' speed result with the fact that in cases of potential collision risks, decisions have to be made in short time (Tam et al. 2009). In general, collision avoidance situations are affected by factors such as: (1) type of ship, (2) traffic categories, (3) weather, (4) navigational technology (Statheros et al. 2008; Szlapczynski 2011). The aforementioned paper describes numerous methods for detecting collision situation and risks, as well as methods for dealing with those 
situations. Szlapczynski and Szlapczynska (2016) conducted an extensive study of domain-based ship collision risk parameters by using elliptic form of vessel's domain and delivered a novel approach to domain violations introducing degree of domain violation and time to domain violation, which contributed to better understanding of domain models within decision support systems.

The concept of the ship domain theory plays a significant role in describing maritime collision avoidance, danger detection and VTS system engineering (Tsou et al. 2010). Ship domain was first mentioned by Fujii, Tanaka (1971) and Goodwin (1975). According to Goodwin (1975), ship domain theory is defined as "the surrounding effective waters, which the navigator of a ship wants to keep clear of other ships or fixed objects". To date, several approaches to designing the ship's domain have been developed (Pietrzykowski 2008; Szlapczynski, Szlapczynska 2017; Wang et al. 2009) and they vary in the aspect of different shapes and sizes, risk assessments, collision avoidance, traffic simulations and optimal trajectory planning. From the standpoint of the master, the most acceptable case of conducting the passage plan is the navigation without interference (Filipowicz 2004). This implies that during the passage, there is no collision avoidance and officers are only focused on conducting the passage plan, i.e. there is no violation of ship's domain.

It can be noticed that in almost all research to date, meteorological and oceanological conditions have not been taken into the account while considering the risks of collision avoidance at sea. Furthermore, in most of the available collision risk research, only the intended deviations for purposes of complying with the COLREG (Convention on the International Regulations for Preventing Collisions at Sea) rules were taken into consideration. Intended ship course changes due to the ship's arrival to the waypoint were not considered. Other approaches that detect collision risks take in consideration only the real-time data, but not the passage plans. Some papers (Filipowicz 2004) reduce the risk detection zones to areas (sectors) of increased danger where the vessels' movement should be closely monitored. In his paper, Smierzchalski (1999) depicts a version of a ship system of evolutionary trajectory planning by introducing ship speed changes on certain navigation segments for purposes of dealing with the final collision risks. Researches by Porretta et al. (2008, 2010) renders a concept of air traffic management on the basis of a $4 \mathrm{D}$ trajectory (3D of space + time). He et al. (2017) delivered a quantitative analysis of COLREG rules integrated with seamanship practices for autonomous collision avoidance at open sea (unrestricted waters). The authors attempted to define a system in which each individual flight will finally be conducted by following the initial planning as closely as possible and the role of the control and management system is the safe flight execution. With reference to the mentioned research, it is likely that future VTS will have the capacity to guide and control ships, which makes the ship control system similar to the air traffic control system.

\section{Model for early detection of collision situations in a VTS area}

\subsection{Segments and meteo-oceanological areas within the vessel passage plans}

We assume that $p$ set of vessels $S_{1}, S_{2}, \ldots, S_{p-1}, S_{p}$ are located in a predefined VTS area and each vessel has a unique passage plan. The Passage Plan $(P P)$ of an arbitrary $j$-th vessel $S_{j}, j \in\{1,2, \ldots, p\}$, is defined by the planned waypoints $w_{i}^{j}=\left(\varphi_{i}^{j}, \lambda_{i}^{j}\right), i=0,1,2, \ldots, m_{j}$, from the set:

$$
P P^{j}=\left\{w_{0}^{j}, w_{1}^{j}, \ldots, w_{m_{j}-1}^{j}, w_{m_{j}}^{j}\right\},
$$

where: $m_{j}$ is the number of the used waypoints in the passage plan of the vessel $S_{j}$.

Usual definition states that a waypoint is a point where ship changes her course. For the purpose of this study, the definition of a waypoint is slightly enhanced in order to cover not only the points where the course is changed but also the points where ship crosses from one meteo-oceanological area $M_{r}, r=1,2, \ldots, m_{r}$, to another, as indicated in Figure 1. Figure 1 presents a simplified visualization of passage plans of any two ships $S_{j}$ and $S_{k}, k \in\{1,2, \ldots, p\}$, $k \neq j$, in the monitored area.

Passage plans for ships $S_{j}$ and $S_{k}$ in Figure 1 consist of waypoints $W_{i}^{j}, i=0,1,2, \ldots, m_{j}$, and $W_{q}^{k}, q=0,1,2, \ldots, m_{k}$ respectively. Waypoints that represent intersections of individual passage plan segments and boundaries of meteooceanological areas are defined by the passage plans of each vessel and associated meteo-oceanological data provided by the appropriate meteorological and hydrological service.

As the entire navigation is conducted on the Earth represented as a geoid, the distances on which the proposed model is applicable are primarily defined by the Legendre's theorem. According to Legendre's theorem, every spherical triangle, the arcs of which are very small when compared to the radius of the sphere on which it sits, can be substituted by a planar triangle with negligible error (Nádeník 2004). Thus, we consider detection of collision situations between vessels separated by up to 60 nautical miles in the monitored area. For this reason, the ship coordinates $(\varphi, \lambda)$ could be transformed into associated planar $(x, y)$ coordinates of some appropriate local reference frame (Figure 1), i.e.:

$$
w_{i}^{j}=\left(\varphi_{i}^{j}, \lambda_{i}^{j}\right) \rightarrow W_{i}^{j}=\left(x_{i}^{j}, y_{i}^{j}\right) .
$$

\subsection{Vessels' passage plan in time domain}

For predicting future positions of vessels and detecting collision situations, it is necessary to know the estimated value of vessel's speed in every segment of the passage plan. If the monitoring is performed under the assumption that relevant vessels maintain consistent navigation as defined by the passage plan, i.e. with stationary conditions of a prime mover and variable environmental loads, then 


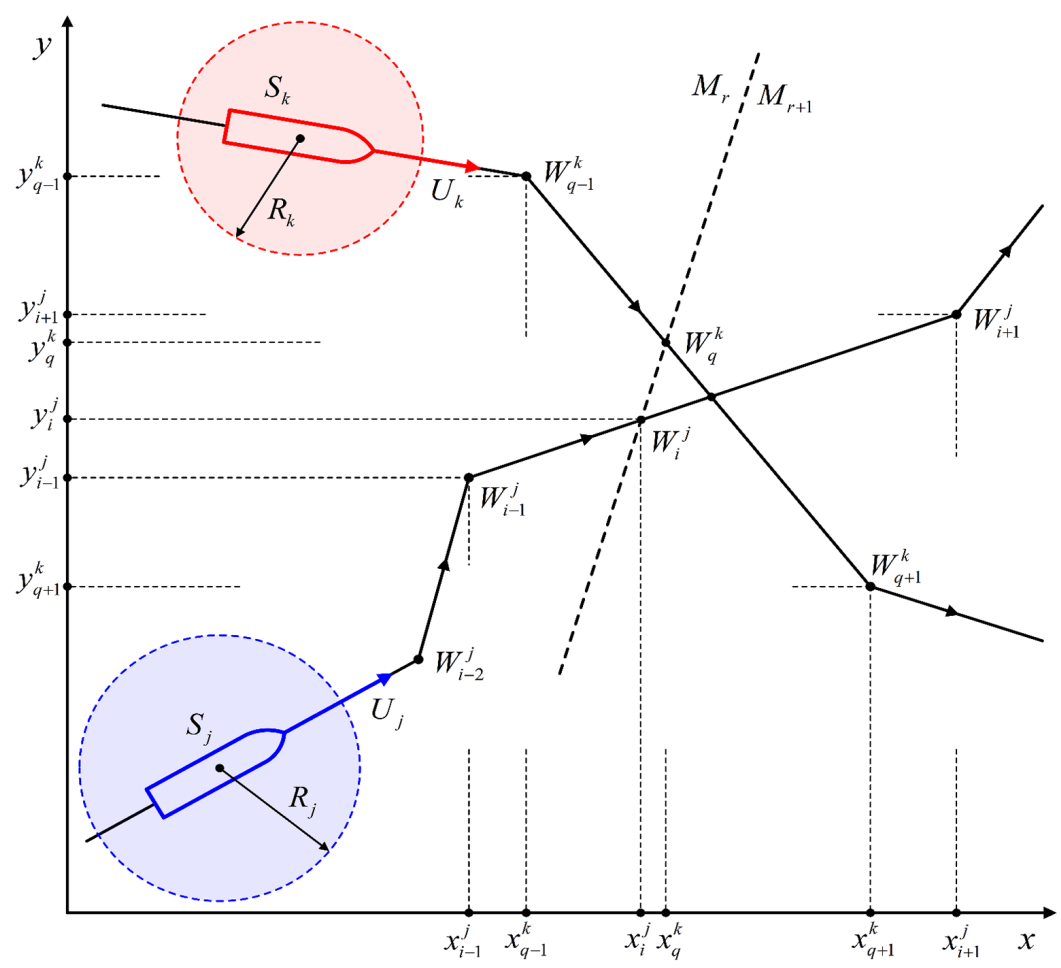

Figure 1. Typical passage plan segments with different meteo-oceanological areas

one can notice that speed of each vessel will be largely dependent on the meteorological and oceanological conditions. In order to define the effect of the aforementioned conditions to the vessel's navigation speed in the area in question, it is necessary to determine environmental loads and their impact on the vessel. We assume that there is more than one relevant meteo-oceanological area within the analysed VTS area, and therefore vessel's speed depends on encounter angle of environmental loads that are related to a course change and movement from one meteo-oceanological area to another.

Considering that VTS organizations monitor limited navigational areas, the model requires localised meteooceanological data of great accuracy. Several multivariate statistical, probabilistic and variational models were developed to provide regional meteo-oceanological overviews, such are Limited Area Model (LAM), HIgh Resolution Limited Area Model (HIRLAM), Global Environmental Multiscale Limited Area Model (GEM-LAM), Regional Modelling System (RAMS) (Gustafsson et al. 2001; Robertson et al. 1999).

It is possible to get various effects on vessel's speed within the same meteo-oceanological area. This largely depends on the vessel's heading in relation to the encounter angle of environmental loads at the observed moment. However, it is important to emphasize that vessel cannot make a turning immediately at some waypoint. In this paper the wheel-over point, turning radius and associated speed loss due to changes of heading near the waypoint have not been taken into consideration.

When the vessel $S_{j}$ reaches waypoint $W_{i}^{j}$, the total motion from the waypoint $W_{0}^{j}\left(1 \leq i \leq m_{j}\right)$ can be expressed in the following vector form:

$$
\begin{aligned}
& \vec{r}_{i}^{j}-\vec{r}_{i-1}^{j}=\vec{W}_{i-1} W_{i}, \text { i.e. } \\
& \vec{r}_{i}^{j}=\vec{r}_{i-1}^{j}+\vec{v}_{i-1, i}^{j} \cdot\left(t_{i}-t_{i-1}\right),
\end{aligned}
$$

which can be further converted into vector components in Cartesian coordinate system:

$$
\begin{aligned}
& x_{i}^{j}=x_{i-1}^{j}+v_{(i-1, i) x}^{j} \cdot\left(t_{i}-t_{i-1}\right) ; \\
& y_{i}^{j}=y_{i-1}^{j}+v_{(i-1, i) y}^{j} \cdot\left(t_{i}-t_{i-1}\right) .
\end{aligned}
$$

By means of (3), each segment of the intended passage between the waypoints can be defined for each vessel within the monitored navigation area separately. For a vessel $S_{j}$, segments defined in this manner could be presented by the following expression:

$$
\vec{r}^{j}(t)= \begin{cases}\vec{r}_{0}^{j}+\vec{v}_{0,1}^{j} \cdot\left(t-t_{0}^{j}\right), & t_{0}^{j} \leq t \leq t_{1}^{j} ; \\ \vec{r}_{0}^{j}+\vec{v}_{0,1}^{j} \cdot\left(t_{1}^{j}-t_{0}^{j}\right)+\vec{v}_{1,2}^{j} \cdot\left(t-t_{1}^{j}\right), & t_{1}^{j} \leq t \leq t_{2}^{j} ; \\ \vdots & \vdots \\ \vec{r}_{0}^{j}+\vec{v}_{0,1}^{j} \cdot\left(t_{1}^{j}-t_{0}^{j}\right)+\ldots+\vec{v}_{i-1, i}^{j} \cdot\left(t-t_{i-1}^{j}\right), & t_{i-1}^{j} \leq t \leq t_{i}^{j} ; \\ \vdots & \vdots \\ \vec{r}_{0}^{j}+\vec{v}_{0,1}^{j} \cdot\left(t_{1}^{j}-t_{0}^{j}\right)+\ldots+\vec{v}_{m_{j}-1, m_{j}}^{j} \cdot\left(t-t_{m_{j}-1}^{j}\right), & t_{m_{j}-1}^{j} \leq t \leq t_{m_{j}}^{j} .\end{cases}
$$

Expression of a passage takes into consideration vessel's speed in a given segment, as well as the vessel's course alteration for the purpose of conducting the passage plan. Defined this way, the expression enables prediction of positions of all vessels in time $t$, which provides the possibility for an early detection of collision situations in a VTS area. 


\subsection{Early detection of collision situations in a VTS area}

Early collision detection model assumes verification of present positions for applicable vessels and predicting their future positions by using geographical or local coordinates. The model is based on the assumption that vessels provide their passage plans to the VTS before entering nominated VTS area. In this manner it is possible to compare all of the submitted passage plans and find critical encounters early. Collision potential analysis is completed and the possible risks are calculated before close quarter situations actually occur. It is necessary to emphasize that the model assumes that vessels navigate according to the submitted version of the passage plans and that deviation from the plan requires resubmission of the plan to the applicable VTS.

In the proposed model of early collision situation detection, ship domain is defined as a circle around the vessel, similarly as in Kao et al. (2007). The size or the radius (Figure 1) of the circle is predefined by the VTS operator, taking into consideration the size of the vessel, speed of the vessel, and type of the vessel, as well as any other data concerning the vessel. Characteristics of the given waterway segment is also taken in consideration. It should be noted that domains do not have to be equal for the entire monitored area, i.e. their radius can vary in relation to the navigation area constraints (coastal sea, channels, etc.), as well as to other external conditions that are to be expected in the waterway.

If it is assumed, without loss of generality, that $R_{j}>R_{k}$, where $R_{j}$ and $R_{k}$ are radii of domain circles of the considered vessels, then the boundary case of domain violation of the vessel $S_{j}$ by the ship $S_{k}$ (Figure 1) can be described by the expression:

$$
\left|\vec{r}^{k}(t)-\vec{r}^{j}(t)\right|=R_{j} .
$$

According to (3), segments of the vessels $S_{j}$ and $S_{k}$ can be shown as:

$$
\begin{aligned}
& \vec{r}_{i}^{j}(t)=\vec{r}_{i-1}^{j}+\vec{v}_{i-1, i}^{j} \cdot\left(t-t_{i-1}\right), t_{i-1}^{j} \leq t \leq t_{i}^{j} ; \\
& \vec{r}_{q}^{k}(t)=\vec{r}_{q-1}^{k}+\vec{v}_{q-1, q}^{k} \cdot\left(t-t_{q-1}\right), t_{q-1}^{k} \leq t \leq t_{q}^{k},
\end{aligned}
$$

i.e., according to (4) and (5) they can be further expressed in Cartesian coordinates as:

$$
\begin{aligned}
& \begin{cases}x_{i}^{j}(t)=x_{i-1}^{j}+v_{(i-1, i) x}^{j} \cdot\left(t-t_{i-1}\right), & t_{i-1}^{j} \leq t \leq t_{i}^{j} ; \\
y_{i}^{j}(t)=y_{i-1}^{j}+v_{(i-1, i) y}^{j} \cdot\left(t-t_{i-1}\right), & t_{i-1}^{j} \leq t \leq t_{i}^{j} ;\end{cases} \\
& \begin{cases}x_{q}^{k}(t)=x_{q-1}^{k}+v_{(q-1, q) x}^{k} \cdot\left(t-t_{q-1}\right), & t_{q-1}^{k} \leq t \leq t_{q}^{k} ; \\
y_{q}^{k}(t)=y_{q-1}^{k}+v_{(q-1, q) y}^{k} \cdot\left(t-t_{q-1}\right), & t_{q-1}^{k} \leq t \leq t_{q}^{k} .\end{cases}
\end{aligned}
$$

From equation (7), the following expression can be obtained:

$$
\left(x_{i}^{j}(t)-x_{q}^{k}(t)\right)^{2}+\left(y_{i}^{j}(t)-y_{q}^{k}(t)\right)^{2}=R_{j}^{2},
$$

which along with (10) and (11) renders a quadratic equation in terms of time $t$ :

$$
a \cdot t^{2}+b \cdot t+c=0,
$$

where coefficients $a, b$, and $c$ have the following values:

$$
\begin{aligned}
& a=\left(v_{(i-1, i) x}^{j}\right)^{2}-2 \cdot v_{(i-1, i) x}^{j} \cdot v_{(q-1, q) x}^{k}+ \\
& \left(v_{(q-1, q) x}^{k}\right)^{2}+\left(v_{(i-1, i) y}^{j}\right)^{2}- \\
& 2 \cdot v_{(i-1, i) y}^{j} \cdot v_{(q-1, q) y}^{k}+\left(v_{(q-1, q) y}^{k}\right)^{2} ; \\
& b=-2 \cdot\left(v_{(i-1, i) x}^{j}\right)^{2} \cdot t_{i-1}-2 \cdot\left(v_{(i-1, i) y}^{j}\right)^{2} \cdot t_{i-1}+ \\
& 2 \cdot v_{(i-1, i) x}^{j} \cdot v_{(q-1, q) x}^{k} \cdot t_{i-1}+2 \cdot v_{(i-1, i) x}^{j} \cdot v_{(q-1, q) x}^{k} \cdot t_{q-1}- \\
& 2 \cdot\left(v_{(q-1, q) x}^{k}\right)^{2} \cdot t_{q-1}+2 \cdot v_{(i-1, i) y}^{j} \cdot v_{(q-1, q) y}^{k} \cdot t_{i-1}+ \\
& 2 \cdot v_{(i-1, i) y}^{j} \cdot v_{(q-1, q) y}^{k} \cdot t_{q-1}-2 \cdot\left(v_{(q-1, q) y}^{k}\right)^{2} \cdot t_{q-1}+ \\
& 2 \cdot v_{(i-1, i) x}^{j} \cdot x_{i-1}^{j}-2 \cdot v_{(q-1, q) x}^{k} \cdot x_{i-1}^{j}- \\
& 2 \cdot v_{(i-1, i) x}^{j} \cdot x_{q-1}^{k}+2 \cdot v_{(q-1, q) x}^{k} \cdot x_{q-1}^{k}+ \\
& 2 \cdot v_{(i-1, i) y}^{j} \cdot y_{i-1}^{j}-2 \cdot v_{(q-1, q) y}^{k} \cdot y_{i-1}^{j}- \\
& 2 \cdot v_{(i-1, i) y}^{j} \cdot y_{q-1}^{k}+2 \cdot v_{(q-1, q) y}^{k} \cdot y_{q-1}^{k} ; \\
& c=-R_{j}^{2}+\left(v_{(i-1, i) x}^{j}\right)^{2} \cdot t_{i-1}^{2}+\left(v_{(i-1, i) y}^{j}\right)^{2} \cdot t_{i-1}^{2}- \\
& 2 \cdot v_{(i-1, i) x}^{j} \cdot v_{(q-1, q) x}^{k} \cdot t_{i-1} \cdot t_{q-1}+\left(v_{(q-1, q) x}^{k}\right)^{2} \cdot t_{q-1}^{2}- \\
& 2 \cdot v_{(i-1, i) y}^{j} \cdot v_{(q-1, q) y}^{k} \cdot t_{i-1} \cdot t_{q-1}+\left(v_{(q-1, q) y}^{k}\right)^{2} \cdot t_{q-1}^{2}- \\
& 2 \cdot v_{(i-1, i) x}^{j} \cdot x_{i-1}^{j} \cdot t_{i-1}+2 \cdot v_{(q-1, q) x}^{k} \cdot x_{i-1}^{j} \cdot t_{q-1}+ \\
& \left(x_{i-1}^{j}\right)^{2}+2 \cdot v_{(i-1, i) x}^{j} \cdot x_{q-1}^{k} \cdot t_{i-1}- \\
& 2 \cdot v_{(q-1, q) x}^{k} \cdot x_{q-1}^{k} \cdot t_{q-1}-2 \cdot x_{i-1}^{j} \cdot x_{q-1}^{k}+ \\
& \left(x_{q-1}^{k}\right)^{2}-2 \cdot v_{(i-1, i) y}^{j} \cdot y_{i-1}^{j} \cdot t_{i-1}+ \\
& 2 \cdot v_{(q-1, q) y}^{k} \cdot y_{i-1}^{j} \cdot t_{q-1}+\left(y_{i-1}^{j}\right)^{2}+ \\
& 2 \cdot v_{(i-1, i) y}^{j} \cdot y_{q-1}^{k} \cdot t_{i-1}-2 \cdot v_{(q-1, q) y}^{k} \cdot y_{q-1}^{k} \cdot t_{q-1}- \\
& 2 \cdot y_{i-1}^{j} \cdot y_{q-1}^{k}+\left(y_{q-1}^{k}\right)^{2} \text {. }
\end{aligned}
$$

As there are three possible quadratic equation solution forms, which depends on the value of the discriminant $D=b^{2}-4 \cdot a \cdot c$. These three cases of domain violation for the considered vessel can be interpreted as: 
1) if $D>0$, the discriminant of the quadratic equation has two different real solutions $t_{1}$ and $t_{2}$. If we presume that $t_{1}<t_{2}$, then $t_{1}$ determines the time of entrance of the vessel $S_{k}$ into the domain of the other vessel $S_{j}$ with larger domain radius $R_{j}>R_{k}$, as indicated by the Figure 2a;

2) if $D=0$, the discriminant of the quadratic equation has one dual real solution $t_{1}=t_{2}$, which describes the boundary case when the vessel with smaller domain radius touches the domain of the other vessel at a single point, as shown in Figure 2b;

3 ) if $D<0$, the discriminant of the quadratic equation has no real solutions, which signifies that no domain violation will occur between the considered vessels in the monitored segments of the planned passage, as shown in Figure 2c.

The above mentioned procedure of domain violation checking should be conducted in terms of the time $t$, i.e. only for those segments of the planned passage that entirely or partially takes place within the time intervals for which the following stands:

$$
\left[t_{i-1}^{j}, t_{i}^{j}\right] \cap\left[t_{q-1}^{k}, t_{q}^{k}\right] \neq \varnothing,
$$

where: $t_{i-1}^{j}$ and $t_{i}^{j}$ present time stamps when vessel $S_{j}$ reaches waypoints $W_{i-1}^{j}$ and $W_{i}^{j}$, respectively (Figure 1 ); similarly, $t_{q-1}^{k}$ and $t_{q}^{k}$ are time stamps when vessel $S_{k}$ reaches waypoints $W_{q-1}^{k}$ and $W_{q}^{k}$, respectively.
Solution of equation (13) when $D \geq 0$ provides time stamp in which domain violation occurs. This time stamp is crucial for early detection of any possible collision situation and when combined with (17) it also provides identification of passage plan segments $\overline{W_{i-1}^{j} W_{i}^{j}}$ and $\overline{W_{q-1}^{k} W_{q}^{k}}$ of ships $S_{j}$ and $S_{k}$, respectively, in which domain violation with high risk of collision could take place. Moreover, this approach can equally handle any two line intersect case, like shown in Figure 3, i.e. no matter if the line segments are co-linear or not.

The above described procedure should be made for any pair of vessels $\left(S_{j}, S_{k}\right), j, k \in\{1,2, \ldots, p\}, j \neq k$, where $p$ is total number of vessels located in some predefined VTS area. In this way, early detection of any possible collision situation can be achieved for all vessels within some area of interest.

Such defined model has the capacity to detect collision situations early, taking into consideration vessel's course alterations predetermined by the passage plan, as well as the effects of meteorological conditions and environmental loads to the vessel's speed. In other words, model can take into account any vessel's speed changes, such are voluntary or involuntary speed reduction due to environmental loads, as well as other speed changing strategies in accordance with the vessel's passage plan (slow steaming, Estimated Time of Arrival (ETA), virtual ETA, etc.). Early recognition of collision situations with an option of automated warnings to the VTS operator, allows enough time to prevent occurrence of potential collision situations. a)

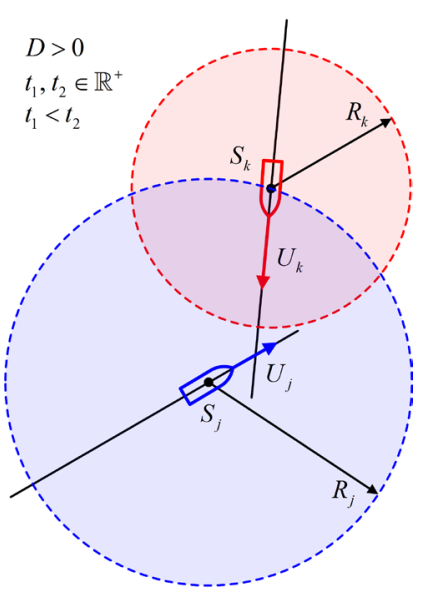

b)

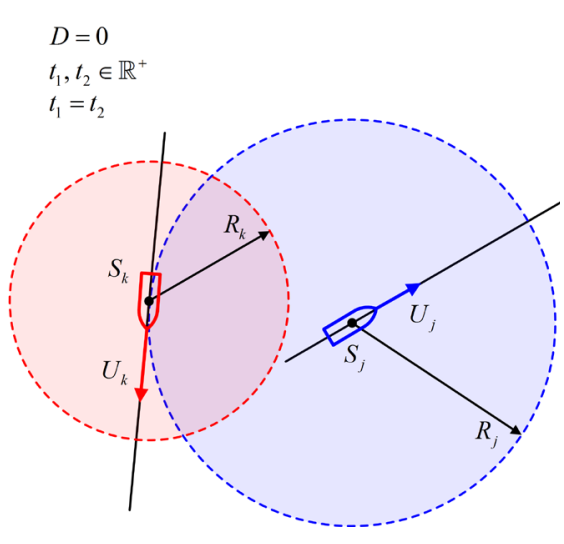

Figure 2. Typical cases of domain violation c)

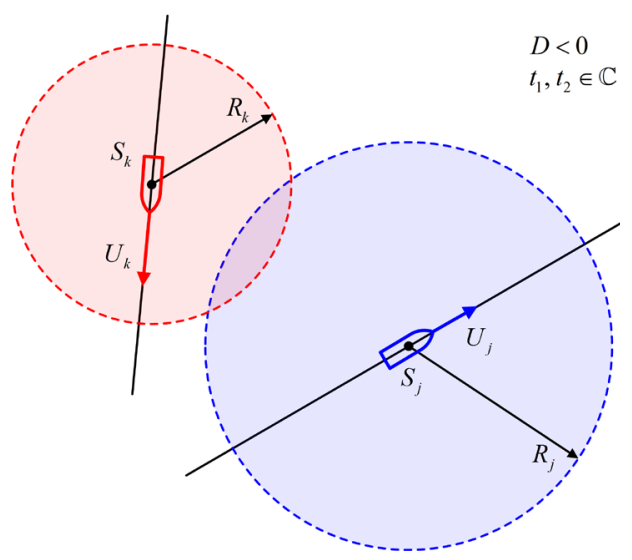

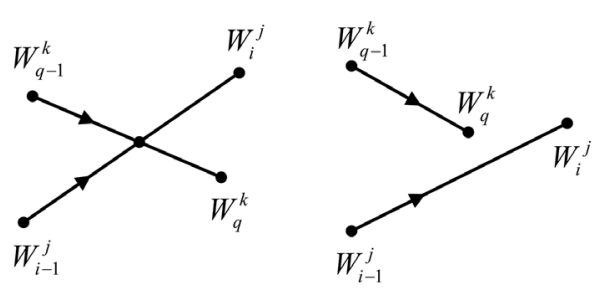
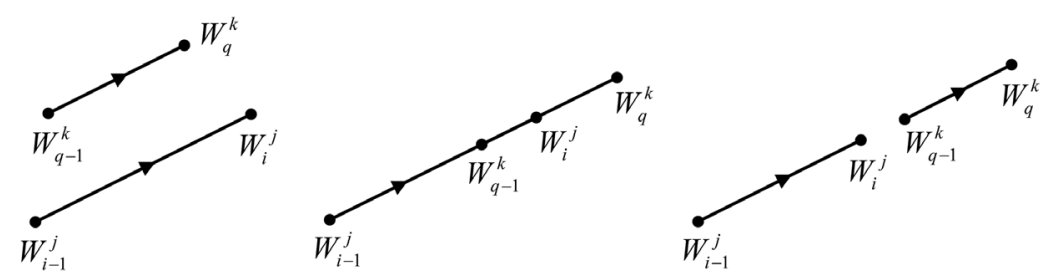

Figure 3. Intersect cases of passage plan segments 


\section{Simulation results and discussion}

In order to evaluate the proposed model for early detection of possible collision situations, a simulation example presents a case of two ships with different passage plans in a VTS area of Northern Adriatic. For the purpose of this case study, navigational simulator Transas NTPRO 5000 (https://transas.com/is-it-real-or-is-it-ntpro-5000) has been selected, together with the simulation models of one container ship (13300 TEU) and one chemical tanker.

The main particulars of these two ships are presented in Table 1. It is important to point out that initial ship speeds listed in Table 1 correspond to the engine loads at Full AHead (FAH) conditions regardless of weather conditions, while the attainable ship speeds obtained during simulations are dependent on predefined environmental loads.

Passage plans for container ship $S_{k}$ and chemical tanker $S_{j}$, with associated waypoints $W_{i}^{j}$ and $W_{q}^{k}$ were reconstructed by using the MarineTraffic (2018) information system, as one of the most commonly used global ship tracking systems, as well as the Transas NTPRO 5000 simulation system with ECDIS module. Thus, reconstructed passage plans are based on the real data for ships operating in the VTS area of Northern Adriatic from Trieste to Rijeka, i.e. from Rijeka towards the Mediterranean Sea.

For the purpose of this simulation example and according to Croatian Meteorological and Hydrological Service (DHMZ 2018), four meteo-oceanological areas have been selected. Environmental conditions for analysed meteorological areas $M_{1}, M_{2}, M_{3}$ and $M_{4}$ are defined in Table 2 and are also shown in Figure 4, where $V_{\text {wind }}$ denotes wind speed $[\mathrm{kn}], \beta_{\text {wind }}$ is wind encounter angle [ $\left.{ }^{\circ}\right]$, $H_{s}$ is significant wave height [m], $T_{p}$ is wave peak period $[s], \beta_{\text {wave }}$ is wave encounter angle [o], $V_{\text {current }}$ is sea current speed $[\mathrm{kn}]$ and $\beta_{\text {current }}$ is wave encounter angle [ $\left.{ }^{\circ}\right]$. Directions of environmental loads are adopted from Transas (2011), as shown in Figure 4, where $u$ is ship speed in surge direction, $v$ is ship speed in sway direction, $U$ is total ship speed over ground $[\mathrm{kn}], \psi$ is ship heading $\left[^{\circ}\right]$ and $\chi$ is ship course over ground $\left[{ }^{\circ}\right]$.

Attainable ship speeds of container ship and chemical tanker in different meteorological areas were obtained by using the Transas NTPRO 5000 navigational simulator. Ship speeds, as well as associated courses, distances and time durations between any two neighbouring waypoints are presented in Table 3 for the container ship, and in Table 4 for the chemical tanker. Passage plans for both ships with associated waypoints and meteorological areas are graphically presented in the Figure 5.
Table 1. Ship particulars for selected container ship and chemical tanker

\begin{tabular}{|l|c|c|}
\hline & $\begin{array}{c}\text { Container ship } \\
(13300 \text { TEU }), S_{k}\end{array}$ & $\begin{array}{c}\text { Chemical } \\
\text { tanker, } S_{j}\end{array}$ \\
\hline Length overall [m] & 365.50 & 182.55 \\
\hline Breadth [m] & 51.65 & 27.34 \\
\hline Draft [m] & 12.50 & 10.85 \\
\hline Displacement [t] & 154191 & 44288 \\
\hline Engine power at FAH [kW] & 21959 & 2955 \\
\hline Engine speed at FAH [rpm] & 62.7 & 85.7 \\
\hline Ship speed at FAH $[\mathrm{kn}]$ & 16.5 & 10.3 \\
\hline Ship domain radius $[\mathrm{nm}]$ & 1.0 & 0.7 \\
\hline
\end{tabular}

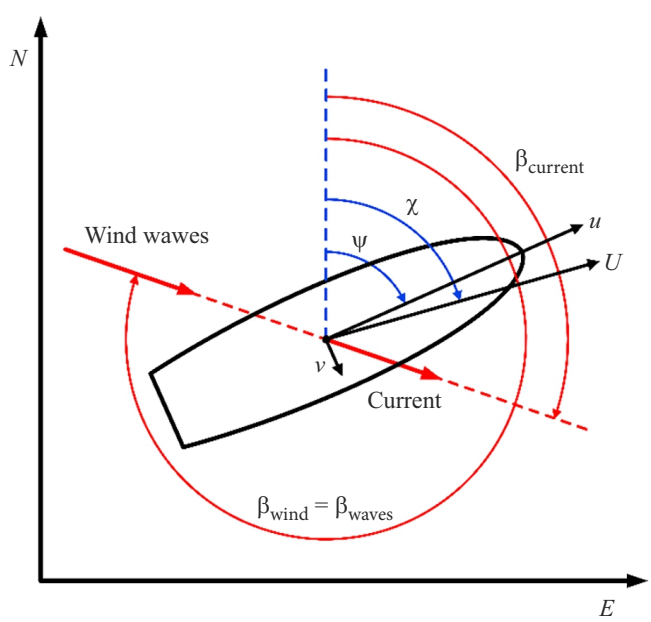

Figure 4. Directions of environmental loads (wind, waves, sea current) with respect to the North axis $N$ and directions of the ship with respect to the ship bow

Environmental loads in the Transas NTPRO 5000 navigation simulator are modelled by using the state-ofthe-art approach. Thus, wind is described as a uniform flow of air around the ship with a constant direction and speed, and all is defined at the height of 6 meters above the sea level. Structural formulae for all aerodynamic hull and superstructure characteristics are defined by the functions that are expressed by the partial sums of the Fourier series (Transas 2011). Sea currents are modelled as a constant flow with a given speed distribution. The sea state is modelled as a stationary process with spectral characteristics that correspond to the real sea wave states. For the wave energy spectral density function, a generalized PiersonMoskowitz spectrum is used with the parameters, which adapt to the navigation area selection (Transas 2011).

Table 2. Environmental conditions for analysed meteorological areas $M_{1}, M_{2}, M_{3}$ and $M_{4}$

\begin{tabular}{|c|c|c|c|c|c|c|c|}
\hline Meteorological area & $V_{\text {wind }}[\mathrm{kn}]$ & $\beta_{\text {wind }}\left[{ }^{\circ}\right]$ & $H_{s}[\mathrm{~m}]$ & $T_{p}[\mathrm{~s}]$ & $\beta_{\text {wave }}\left[^{\circ}\right]$ & $V_{\text {current }}[\mathrm{kn}]$ & $\beta_{\text {current }}\left[{ }^{\circ}\right]$ \\
\hline$M_{1}$ & 25.0 & 320.0 & 2.5 & 6.3 & 320.0 & 0.5 & 140.0 \\
\hline$M_{2}$ & 27.0 & 330.0 & 3.0 & 7.5 & 330.0 & 0.7 & 150.0 \\
\hline$M_{3}$ & 20.0 & 30.0 & 2.0 & 5.8 & 30.0 & 0.4 & 210.0 \\
\hline$M_{4}$ & 15.0 & 45.0 & 1.7 & 5.3 & 45.0 & 0.2 & 190.0 \\
\hline
\end{tabular}


Table 3. Passage plan in time domain for container ship $S_{k}$ with attainable ship speeds regarding the various meteorological areas and associated environmental loads

\begin{tabular}{|c|c|c|c|c|c|c|c|}
\hline Waypoint & Position & Area & Distance [nm] & Speed [kn] & Course [o] & Time [h:min:s] & Duration h:min:s] \\
\hline$W_{0}^{k}$ & $\begin{array}{l}45.6296^{\circ} \mathrm{N} \\
13.5379^{\circ} \mathrm{E}\end{array}$ & $M_{1}$ & - & 15.12 & 245.9 & $00: 00: 00$ & - \\
\hline$W_{1}^{k}$ & $\begin{array}{l}45.5518^{\circ} \mathrm{N} \\
13.2903^{\circ} \mathrm{E}\end{array}$ & $M_{1}$ & 11.39 & 15.82 & 229.4 & $00: 45: 12$ & $00: 45: 12$ \\
\hline$W_{2}^{k}$ & $\begin{array}{l}45.3853^{\circ} \mathrm{N} \\
13.0144^{\circ} \mathrm{E}\end{array}$ & $M_{1}$ & 15.21 & 18.70 & 167.7 & $01: 42: 53$ & $00: 57: 41$ \\
\hline$W_{3}^{k}$ & $\begin{array}{l}45.1080^{\circ} \mathrm{N} \\
13.1003^{\circ} \mathrm{E}\end{array}$ & $M_{1}$ & 17.12 & 17.95 & 145.0 & $02: 37: 49$ & $00: 54: 56$ \\
\hline$W_{4}^{k}$ & $\begin{array}{l}44.8073^{\circ} \mathrm{N} \\
13.3965^{\circ} \mathrm{E}\end{array}$ & $M_{1} / M_{2}$ & 21.94 & 18.03 & 145.0 & $03: 51: 09$ & $01: 13: 20$ \\
\hline$W_{5}^{k}$ & $\begin{array}{l}44.5331^{\circ} \mathrm{N} \\
13.6666^{\circ} \mathrm{E}\end{array}$ & $M_{2}$ & 20.00 & 15.94 & 67.1 & $04: 57: 42$ & $01: 06: 33$ \\
\hline$W_{6}^{k}$ & $\begin{array}{l}44.6236^{\circ} \mathrm{N} \\
13.9663^{\circ} \mathrm{E}\end{array}$ & $M_{2}$ & 14.06 & 14.13 & 43.3 & $05: 50: 38$ & $00: 52: 56$ \\
\hline$W_{7}^{k}$ & $\begin{array}{l}44.6538^{\circ} \mathrm{N} \\
14.0062^{\circ} \mathrm{E}\end{array}$ & $M_{2} / M_{3}$ & 2.49 & 12.57 & 43.3 & $06: 01: 12$ & $00: 10: 34$ \\
\hline$W_{8}^{k}$ & $\begin{array}{l}44.7541^{\circ} \mathrm{N} \\
14.1386^{\circ} \mathrm{E}\end{array}$ & $M_{3}$ & 8.26 & 12.65 & 16.4 & $06: 40: 38$ & $00: 39: 26$ \\
\hline
\end{tabular}

Table 4. Passage plan in time domain for chemical tanker $S_{j}$ with attainable ship speeds regarding the various meteorological areas and associated environmental loads

\begin{tabular}{|c|c|c|c|c|c|c|c|}
\hline Waypoint & Position & Area & Distance $[\mathrm{nm}]$ & Speed [kn] & Course [o] & Time [h:min:s] & Duration [h:min:s] \\
\hline$W_{0}^{j}$ & $\begin{array}{l}45.2497^{\circ} \mathrm{N} \\
14.4453^{\circ} \mathrm{E}\end{array}$ & $M_{4}$ & - & 10.29 & 241.0 & $02: 37: 57$ & - \\
\hline$W_{1}^{j}$ & $\begin{array}{l}45.1797^{\circ} \mathrm{N} \\
14.2670^{\circ} \mathrm{E}\end{array}$ & $M_{4}$ & 8.61 & 10.31 & 199.6 & $03: 28: 09$ & $00: 50: 12$ \\
\hline$W_{2}^{j}$ & $\begin{array}{l}45.1330^{\circ} \mathrm{N} \\
14.2435^{\circ} \mathrm{E}\end{array}$ & $M_{4}$ & 3.00 & 10.29 & 189.1 & $03: 45: 37$ & $00: 17: 28$ \\
\hline$W_{3}^{j}$ & $\begin{array}{l}45.1001^{\circ} \mathrm{N} \\
14.2370^{\circ} \mathrm{E}\end{array}$ & $M_{4} / M_{3}$ & 2.01 & 10.42 & 189.1 & $03: 57: 20$ & $00: 11: 43$ \\
\hline$W_{4}^{j}$ & $\begin{array}{l}45.0672^{\circ} \mathrm{N} \\
14.2286^{\circ} \mathrm{E}\end{array}$ & $M_{3}$ & 2.00 & 10.42 & 189.8 & $04: 08: 51$ & $00: 11: 31$ \\
\hline$W_{5}^{j}$ & $\begin{array}{l}44.9517^{\circ} \mathrm{N} \\
14.2004^{\circ} \mathrm{E}\end{array}$ & $M_{3}$ & 7.02 & 10.46 & 201.4 & $04: 49: 16$ & $00: 40: 25$ \\
\hline$W_{6}^{j}$ & $\begin{array}{l}44.7528^{\circ} \mathrm{N} \\
14.0907^{\circ} \mathrm{E}\end{array}$ & $M_{3}$ & 12.82 & 10.43 & 191.2 & $06: 02: 48$ & $01: 13: 32$ \\
\hline$W_{7}^{j}$ & $\begin{array}{l}44.6446^{\circ} \mathrm{N} \\
14.0608^{\circ} \mathrm{E}\end{array}$ & $M_{3}$ & 6.61 & 10.26 & 166.1 & $06: 40: 49$ & $00: 38: 01$ \\
\hline
\end{tabular}

In order to simplify the simulations, it is assumed that all external disturbances are coming from the same direction. Moreover, it is also assumed that the ship retains its given course regardless of the environmental loads, thus the ship's autopilot for tracking the planned voyage ("tracking control" or "tracking mode") is used. Each of the defined scenarios was simulated within a period of $20 \mathrm{~min}$, and the speed of the considered ship in the simulated scenario was determined as the average value based on the last 10 min. As already mentioned, the wheel-over point, turning radius and associated speed loss due to changes of heading near the waypoint have not been taken into account in this paper, nor in this simulation example.
Time stamps in Tables 3 and 4, in which the selected ship reaches the appropriate waypoint consider the final CPA to be equal to zero in this simulation. In other words, time stamps have been defined in such manner that the collision of analysed ships is ensured in accordance to their passage plans and attainable ship speeds while considering various courses and meteorological areas.

As previously defined in the theoretical part of this paper, the first step in the process of early detection of collision situations is checking all segments of the planned passage in order to detect only the segments that will take place within the time intervals for which the relation (17) stands. Thus, as a result of this analysis, only the time seg- 


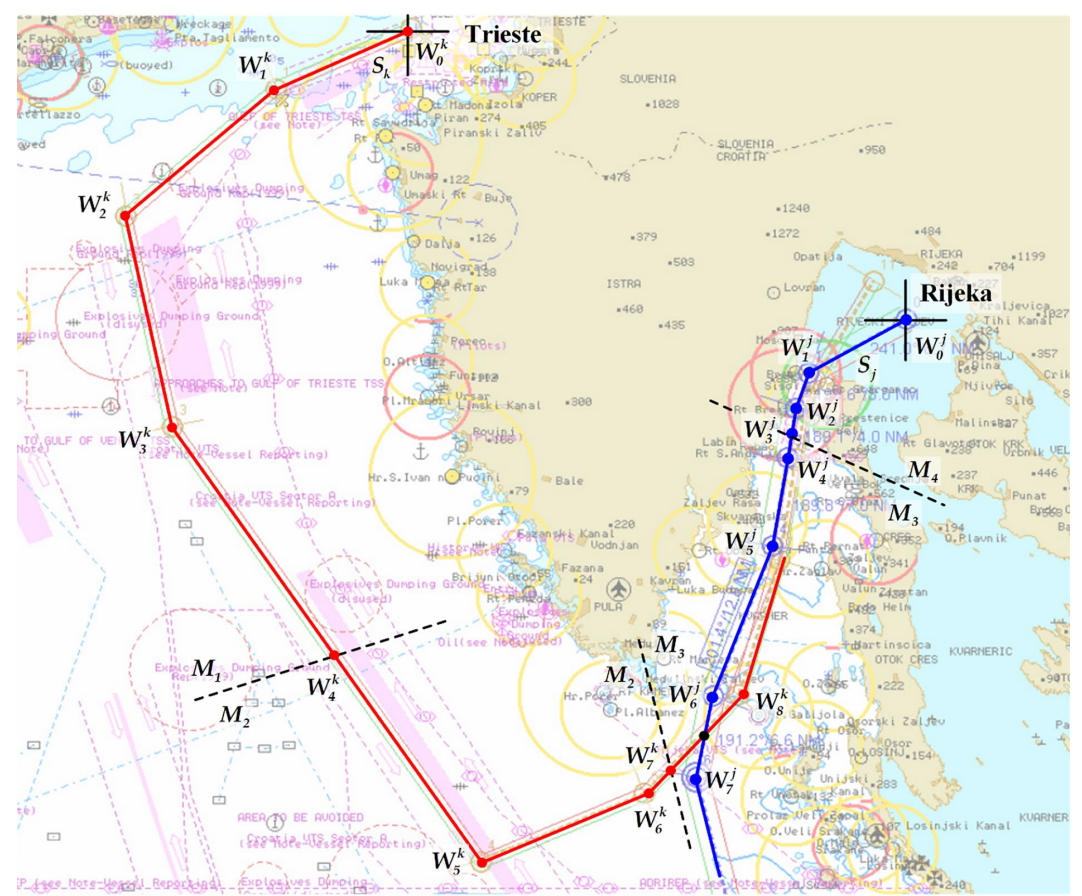

Figure 5. Visualization of passage plans and appropriate waypoints for selected container ship $S_{k}$ and chemical tanker $S_{j}$ with associated meteo-oceanological areas

ments $\left[t_{7}^{k}, t_{8}^{k}\right]$ and $\left[t_{6}^{j}, t_{7}^{j}\right]$ are of the particular interest. Namely according to the terms (13)-(16), the selected ship domains (Table 1), and ship positions with time stamps (Tables 3 and 4), discriminant of the quadratic equation (13) depicts $D>0$, which means that chemical tanker will undoubtedly enter the domain of the container ship $\left(R_{k}>R_{j}\right)$ between the waypoints $W_{6}^{j}$ and $W_{7}^{j}$, similarly like in Figure $2(a)$.

If, without loss of generality in selection of initial time stamps, one assumes that $t_{0}^{k}=00: 00: 00$ [h:min:s] and $t_{0}^{j}=02: 37: 57$, collision of analysed ships will take place at $t_{\text {collision }}^{k, j}=06: 19: 46$ at position defined as $\overline{W_{7}^{k} W_{8}^{k}} \cap \overline{W_{6}^{j} W_{7}^{j}}$. However, the solution of quadratic equation (13) provides even more appropriate time of container ship domain violation by approaching the chemical tanker. This domain violation occurs at $t_{\text {domain }}^{k, j}=06: 17: 06$, and therefore this time stamp is essential in the early detection of possible collision situations. By knowing this time stamp in advance, and considering that in this case $t_{0}^{j}>t_{0}^{k}$, one can easily conclude that the early detection of domain violation in this example is possible in $\Delta t=t_{\text {domain }}^{k, j}-t_{0}^{j}=03: 39: 09$ prior to this highly risky event. In comparison with this proposed approach, VTS operators and ship mates on-board will detect possible collision situation at the time stamp $t_{6}^{j}=06: 02: 48>t_{7}^{k}$ when both ships are sailing at their final courses before the collision, i.e. only $\Delta t_{V T S}=t_{\text {domain }}^{k, j}-t_{6}^{j}=0: 14: 18$ prior to the event of domain violation. In other words, the early detection of possible collision situation in this example could be achieved even $\Delta t-\Delta t_{V T S}=3: 24: 51$ earlier by using the approach proposed in this paper in comparison to possibilities of conventional VTS systems. It should be emphasized that this significant advantage of the proposed model for early detection of possible collision situations is achieved by taking into account the complete passage plans with the estimated ship speeds due to ship course changing and shifting of ships from one meteorological area to another.

If the ship's speed changes are not taken into the account, then the similar early detection of possible collision situations could be achieved by using the ship's speeds at the time stamp $t_{0}^{j}=02: 37: 57$ only, i.e. after chemical tanker enters the VTS area. It can be easily noticed that the speed of container ship at this time stamp will be 17.95 $\mathrm{kn}$ and speed of chemical tanker will be $10.29 \mathrm{kn}$. Only if these ship speeds are used, the container ship will reach the intersection point $\overline{W_{7}^{k} W_{8}^{k}} \cap \overline{W_{6}^{j} W_{7}^{j}}$ at $t^{k}=06: 06: 18$, and chemical tanker will reach this point at $t^{j}=06: 21: 55$. This means that even the approach proposed in this paper could not detect the possible collision situation without the accurate estimation of ship speeds throughout all the segments of the passage plan. This directly arises from the time difference of $t^{j}-t^{k}=00: 15: 37$ calculated in this manner; this means that it could be wrongly concluded that there is no evident domain violation.

Although this simulation example takes into consideration only two ships at a time, the same approach could be taken for any pair of ships within any VTS area of interest. In that way, this approach can easily be used for multi ship encounter and early detection of possible collision situations, as theoretically described in the previous chapter. 
The simulation results prove how early detection model could help in recognition of potential collisions or even dangerous close quarter situation that may arise between ships. The results also show how the model can be used in demanding situation, where neighbouring meteo-oceanological areas can have significantly different features, causing noticeable change of ship's speed. In addition, proposed approach shows that detection of collision situations can be discovered significantly earlier so VTS operator would have enough time to inform ships and avoid critical situation. The simulation undoubtedly can increase safer passage of ships enabling enhanced collision avoidance approach.

\section{Conclusions}

Considering the significant global fleet expansion in recent years and substantial increase of traffic density in specific areas, it is reasonable to assume that VTS services should be developed as organizations with enhanced capabilities and focus on adjusting towards new regulatory roles. This study presents new approach that offers the operators possibility to control the entire navigable area within a VTS sector by providing more innovative and reliable approach to maritime traffic monitoring and control. Existing VTS services are mostly focused on the area-monitoring concept of collision detection. Such approach, in the areas with very dense traffic, increases likelihood of operator errors when anticipating collision situations across the entire controlled area. Available research papers commonly deal with the detection of collision by elaborating relative or true values of the course and speed obtained by radar or AIS. However, these approaches do not take into account various changes of vessel course and speed, thus limiting prediction of possible collisions. This is particularly important in coastal areas that are usually covered by VTS surveillance, and where changing of course and speed frequently occurs.

The proposed model for early detection of possible collision situation is based on the assumption that nominated VTS is provided with passage plans of all the vessels that are located, or will soon be located in the monitored area. In order to implement all the characteristics of any individual passage plan, the vessel passage plan has been modelled in the time domain, i.e. parameterization of passage plans in terms of time has been conducted. In this paper, the definition of the waypoint is slightly enhanced in order to cover the points where the course was changed, as well as to cover the points where ship crosses from one meteo-oceanological area to another.

Therefore, the variations of environmental and weather conditions throughout the monitored area have been implemented in terms of meteo-oceanological areas characterized with the wind speed and direction, current speed and direction, significant wave height, wave period and wave direction. These environmental data are essential for the estimation of environmental loads affecting the ship, i.e. for estimation of ship's speed in order to more accurately and reliably detect possible collision situations. Hence, it is assumed that any ship in the monitored area can sail through more than one relevant meteo-oceanological area. Therefore, the proposed model also analyses how encounter angles of environmental loads, together with course changing and ship shifting from one meteooceanological area to another, affect vessel's speed.

In this particular case, ship's domain is defined as a circle around the vessel. The characteristic cases of such domain violation are accordingly emphasized. For this circular ship domain, a quadratic equation model was analysed in terms of time in which domain violation would occur. The results indicate that there are three cases of domain violation for the vessel in question, but only two of them are relevant for early detection of possible collision situations. The first situation is when the vessel with smaller domain enters the domain of the vessel with larger domain. The second situation is when the vessel with smaller domain touches the domain of the other vessel at a single point, which actually presents a boundary case. However, the solution of aforementioned quadratic equation model estimates the time stamp in which domain violation occurs. Detection of possible collision situations between any two ships in monitored area regardless of geometrical characteristics of the passage plan segment is the most important advantage of this approach. Thus, this approach can equally handle situations when the final passage plan segments are co-linear, i.e. parallel, as well as when they are not co-linear, i.e. when they intersect in only one point. It is beneficial to point out that this approach is not constrained by the number of vessels in a monitored area. In this way, early detection of any possible collision situation can be achieved for all vessels within some area of interest.

The results of enclosed simulation clearly show advantages of the proposed model when passage plans are combined with the analysis of environmental loads. This approach discovered that it is crucial to accurately estimate ship's speed in each individual passage plan segments with respect to various courses and environmental loads. Moreover, through presented results, it is possible to conclude that estimation of collision potential is not reliable without taking environmental factors into account. Additionally, the simulation results indicate the significant advantage of the proposed approach when we compare it to conventional VTS systems. This particularly refers to the additional time difference that arises between the time stamp in which collision situation could be detected by the proposed approach and the time stamp in which collision situation is detected by a VTS system, i.e. a VTS operator. This significant time difference gives the VTS operators and crewmembers on-board the monitored ships additional time frame for taking the appropriate measures in order to avoid dangerous situations in advance, with substantially smaller risk. It should be emphasized that this model provides a decision support tool for a VTS operator, but it does not provide a solution for carrying out the appropriate actions when detecting dangerous situations. 
Besides the above-mentioned advantages of the proposed approach, several limitations should be pointed out that can serve as the guidelines for the future work. Further research should consider integration of the hydrodynamic models for estimation of attainable ship speed for various environmental loads with different encounter angles that could be applied on sufficiently large class of various ship types and different engine loads. Moreover, the implementation of properties that affect the ship's speed close to conventional waypoints should also be included in enhancement of the proposed model. This primarily refers to the wheel-over point manoeuvre, as well as for turning radius and the associated speed loss due to the changes of heading near the waypoint. There is also the need to systematically research and analyse how dynamic updating of changes related to passage plans and environmental loads affect the early detection of domain violation.

Finally, regulation plays a significant role in developing VTS navigational management within the surveyed area. At this moment, most of the VTS organizations support ships through navigation advisories transmitted to vessels sailing within confined and dense traffic areas. Therefore, there is a need to create international regulations so that the VTS operators could control traffic situations in a similar way as the Air Traffic Control. In such manner, VTS operators would be able to enforce traffic control, reduce navigational uncertainties, and separate vessels with the higher collision risk.

\section{Acknowledgements}

This work has been supported by the Croatian Science Foundation under the project IP-2018-01-3739 (DESSERT - DEcision Support System for green and safE ship RouTing).

\section{Disclosure statement}

The authors whose names are listed above certify that they have no affiliations with or involvement in any organization or entity with any financial interest (such as honoraria; educational grants; participation in speakers' bureaus; membership, employment, consultancies, stock ownership, or other equity interest; and expert testimony or patent-licensing arrangements), or non-financial interest (such as personal or professional relationships, affiliations, knowledge or beliefs) in the subject matter or materials discussed in this manuscript.

\section{References}

Bukhari, A. C.; Tusseyeva, I.; Lee, B.-G.; Kim, Y.-G. 2013. An intelligent real-time multi-vessel collision risk assessment system from VTS view point based on fuzzy inference system, Expert Systems with Applications 40(4): 1220-1230. https://doi.org/10.1016/j.eswa.2012.08.016

Chauvin, C.; Lardjane, S.; Morel, G.; Clostermann, J.-P.; Langard, B. 2013. Human and organisational factors in maritime acci- dents: Analysis of collisions at sea using the HFACS, Accident Analysis \& Prevention 59: 26-37.

https://doi.org/10.1016/j.aap.2013.05.006

DHMZ. 2018. ALADIN/HR - Wind Dynamical Adaptation for Istra \& Kvarner. Croatian Meteorological and Hydrological Service (Državni hidrometeorološki zavod - DHMZ). Available from Internet: http://meteo.hr/index_en.php

Donderi, D. C.; Mercer, R.; Hong, M. B.; Skinner, D. 2004. Simulated navigation performance with marine electronic chart and information display systems (ECDIS), Journal of Navigation 57(2): 189-202.

https://doi.org/10.1017/S0373463304002668

Filipowicz, W. 2004. Vessel traffic control problems, Journal of Navigation 57(1): 15-24.

https://doi.org/10.1017/S0373463303002480

Fujii, Y.; Tanaka, K. 1971. Traffic capacity, Journal of Navigation 24(4): 543-552. https://doi.org/10.1017/S0373463300022384

Goerlandt, F.; Kujala, P. 2011. Traffic simulation based ship collision probability modeling, Reliability Engineering \& System Safety 96(1): 91-107.

https://doi.org/10.1016/j.ress.2010.09.003

Goodwin, E. M. 1975. A statistical study of ship domains, Journal of Navigation 28(3): 328-344.

https://doi.org/10.1017/S0373463300041230

Gran, S. 1999. The impact of transportation on wildlife in the Malacca Straits, TED Case Studies 9(3): 573.

Gustafsson, N.; Berre, L.; Hörnquist, S.; Huang, X.-Y.; Lindskog, M.; Navascués, B.; Mogensen, K. S.; Thorsteinsson, S. 2001. Three-dimensional variational data assimilation for a limited area model, Tellus A: Dynamic Meteorology and Oceanography 53(4), 425-446.

https://doi.org/10.3402/tellusa.v53i4.12198

Harati-Mokhtari, A.; Wall, A.; Brooks, P.; Wang, J. 2007. Automatic identification system (AIS): data reliability and human error implications, Journal of Navigation 60(3): 373-389. https://doi.org/10.1017/S0373463307004298

He, Y.; Jin, Y.; Huang, L.; Xiong, Y.; Chen, P.; Mou, J. 2017. Quantitative analysis of COLREG rules and seamanship for autonomous collision avoidance at open sea, Ocean Engineering 140: 281-291. https://doi.org/10.1016/j.oceaneng.2017.05.029

ISL. 2018. World merchant fleet, in Shipping Statistics and Market Review 62(1/2), Institute of Shipping Economics and Logistics (ISL), Bremen, Germany, $62 \mathrm{p}$.

Kao, S.-L.; Lee, K.-T.; Chang, K.-Y.; Ko, M.-D. 2007. A fuzzy logic method for collision avoidance in vessel traffic service, Journal of Navigation 60(1): 17-31.

https://doi.org/10.1017/S0373463307003980

Kim, M.; Hizir, O.; Turan, O.; Day, S.; Incecik, A. 2017. Estimation of added resistance and ship speed loss in a seaway, Ocean Engineering 141: 465-476. https://doi.org/10.1016/j.oceaneng.2017.06.051

Kop, G. 1990. General principles of VTS and the IMO guidelines, in D. J. Sanders (Ed.). The Nautical Institute on Pilotage and Shiphandling, 205-208.

Last, P.; Hering-Bertram, M.; Linsen, L. 2015. How automatic identification system (AIS) antenna setup affects AIS signal quality, Ocean Engineering 100: 83-89. https://doi.org/10.1016/j.oceaneng.2015.03.017

Lind, M.; Bergmann, M.; Hägg, M.; Karlsson, F.; Siwe, U.; Watson, R. T. 2018. Sea traffic management - the route to the future, in Proceedings of the 17th Conference on Computer Applications and Information Technology in the Maritime Industries COMPIT'18, 14-16 May 2018, Pavone, Italy, 504-509. 
Liu, Z.; Liu, J.; Li, Z.; Liu, R. W.; Xiong, N. 2017. Characteristics analysis of vessel traffic flow and its mathematical model, Journal of Marine Science and Technology 25(2): 230-241. https://doi.org/10.6119/JMST-017-0109-1 (in Chinese).

Mao, W.; Rychlik, I.; Wallin, J.; Storhaug, G. 2016. Statistical models for the speed prediction of a container ship, Ocean Engineering 126: 152-162.

https://doi.org/10.1016/j.oceaneng.2016.08.033

MarineTraffic. 2018. Global Ship Tracking Intelligence. Available from Internet: https://www.marinetraffic.com

Mou, J. M.; Van der Tak, C.; Ligteringen, H. 2010. Study on collision avoidance in busy waterways by using AIS data, Ocean Engineering 37(5-6): 483-490.

https://doi.org/10.1016/j.oceaneng.2010.01.012

Nádeník, Z. 2004. Legendre theorem on spherical triangles, in 50 years of the Research Institute of Geodesy, Topography and Cartography, Zdiby, Czech Republic, 41-48.

Ou, Z.; Zhu, J. 2008. AIS database powered by GIS technology for maritime safety and security, Journal of Navigation 61(4): 655-665. https://doi.org/10.1017/S0373463308004888

Pietrzykowski, Z. 2008. Ship's fuzzy domain - a criterion for navigational safety in narrow fairways, Journal of Navigation 61(3): 499-514. https://doi.org/10.1017/S0373463308004682

Porretta, M.; Dupuy, M.-D.; Schuster, W.; Majumdar, A.; Ochieng, W. 2008. Performance evaluation of a novel $4 \mathrm{~d}$ trajectory prediction model for civil aircraft, Journal of Navigation 61(3): 393-420. https://doi.org/10.1017/S0373463308004761

Porretta, M.; Schuster, W.; Majumdar, A.; Ochieng, W. 2010. Strategic conflict detection and resolution using aircraft intent information, Journal of Navigation 63(1): 61-88. https://doi.org/10.1017/S0373463309990270

Prpić-Oršić, J.; Faltinsen, O. M. 2012. Estimation of ship speed loss and associated $\mathrm{CO}_{2}$ emissions in a seaway, Ocean Engineering 44: 1-10.

https://doi.org/10.1016/j.oceaneng.2012.01.028

Robertson, L.; Langner, J.; Engardt, M. 1999. An Eulerian limited-area atmospheric transport model, Journal of Applied Meteorology 38(2): 190-210.

https://doi.org/10.1175/1520-0450(1999)038\%3C0190:AELA AT\%3E2.0.CO;2

Rudan, I.; Komadina, P.; Ivče, R. 2012. Officers' subjective near miss notion in situations of collision avoidance at sea, Promet - Traffic \& Transportation 24(4): 317-322.

https://doi.org/10.7307/ptt.v24i4.441

Sang, L.-Z.; Wall, A.; Mao, Z.; Yan, X.-P.; Wang, J. 2015. A novel method for restoring the trajectory of the inland waterway ship by using AIS data, Ocean Engineering 110: 183-194. https://doi.org/10.1016/j.oceaneng.2015.10.021

Smierzchalski, R. 1999. Evolutionary trajectory planning of ships in navigation traffic areas, Journal of Marine Science and Technology 4(1): 1-6. https://doi.org/10.1007/s007730050001

Statheros, T.; Howells, G.; Maier, K. 2008. Autonomous ship collision avoidance navigation concepts, technologies and techniques, Journal of Navigation 61(1): 129-142. https://doi.org/10.1017/S037346330700447X

STM. 2015. MONALISA 2.0. EU Project. Sea Traffic Management (STM), Swedish Maritime Administration. Available from Internet: https://www.stmvalidation.eu/projects/monalisa-2

STM. 2018a. STM EfficientFlow. EU Project. Sea Traffic Management (STM), Swedish Maritime Administration. Available from Internet: https://www.stmvalidation.eu/projects/efficientflow
STM. 2018b. STM Validation Project. EU Project. Sea Traffic Management (STM), Swedish Maritime Administration. Available from Internet: https://www.stmvalidation.eu/projects/stm-validation

Su, C.-M.; Chang, K.-Y.; Cheng, C.-Y. 2012. Fuzzy decision on optimal collision avoidance measures for ships in vessel traffic service, Journal of Marine Science and Technology 20(1): $38-48$.

Szlapczynski, R. 2011. Evolutionary sets of safe ship trajectories: a new approach to collision avoidance, Journal of Navigation 64(1): 169-181. https://doi.org/10.1017/S0373463310000238

Szlapczynski, R.; Szlapczynska, J. 2016. An analysis of domainbased ship collision risk parameters, Ocean Engineering 126: 47-56. https://doi.org/10.1016/j.oceaneng.2016.08.030

Szlapczynski, R.; Szlapczynska, J. 2017. Review of ship safety domains: models and applications, Ocean Engineering 145: 277-289. https://doi.org/10.1016/j.oceaneng.2017.09.020

Tam, C. K.; Bucknall, R.; Greig, A. 2009. Review of collision avoidance and path planning methods for ships in close range encounters, Journal of Navigation 62(3): 455-476. https://doi.org/10.1017/S0373463308005134

Transas. 2011. Description of Transas Mathematical Model. Version 02.08, Transas Ltd. Available from Internet: https://www.transas.com

Tsou, M.-C. 2010a. Discovering knowledge from ais database for application in VTS, Journal of Navigation 63(3): 449-469. https://doi.org/10.1017/S0373463310000135

Tsou, M.-C. 2010b. Integration of a geographic information system and evolutionary computation for automatic routing in coastal navigation, Journal of Navigation 63(2): 323-341. https://doi.org/10.1017/S0373463309990385

Tsou, M.-C. 2016. Multi-target collision avoidance route planning under an ECDIS framework, Ocean Engineering 121: 268-278. https://doi.org/10.1016/j.oceaneng.2016.05.040

Tsou, M.-C.; Kao, S.-L.; Su, C.-M. 2010. Decision support from genetic algorithms for ship collision avoidance route planning and alerts, Journal of Navigation 63(1): 167-182. https://doi.org/10.1017/S037346330999021X

Valčić, M.; Antonić, R.; Tomas, V. 2011. ANFIS based model for ship speed prediction, Brodogradnja / Shipbuilding 62(4): 373-382.

Wang, N.; Meng, X.; Xu, Q.; Wang, Z. 2009. A unified analytical framework for ship domains, Journal of Navigation 62(4): 643-655. https://doi.org/10.1017/S0373463309990178

Westerlund, K. 2010. The Collection of FSA Studies in the Baltic Sea Area. Efficient, Safe and Sustainable Traffic at Sea (EfficienSea): Baltic Sea Region Programme 2007-2013. Deliverable No. D WP6 4 05. Contract No. 013. 49 p. Available from Internet: http://efficiensea.org/files/mainoutputs/wp6/d_wp6_4_2.pdf

Zhang, W.; Goerlandt, F.; Kujala, P.; Wang, Y. 2016. An advanced method for detecting possible near miss ship collisions from AIS data, Ocean Engineering 124: 141-156. https://doi.org/10.1016/j.oceaneng.2016.07.059

Zhang, W.; Goerlandt, F.; Montewka, J.; Kujala, P. 2015. A method for detecting possible near miss ship collisions from AIS data, Ocean Engineering 107: 60-69.

https://doi.org/10.1016/j.oceaneng.2015.07.046 